\title{
Patient Initiated Side Effects Reporting System in their Vernacular Language: A Cross Sectional Analysis of Feasibility and Acceptability in Our Scenario
}

\author{
Krishnan Vengadaragava Chary ${ }^{1, *}$, Karthik VP ${ }^{2}$ \\ Department of Pharmacology, Panimalar Medical College Hospital and Research Institute, Chennai, Tamil Nadu, INDIA. \\ 2Department of Pharmacology, Sri Ramachandra Medical College, Porur, Chennai, Tamil Nadu, INDIA.
}

\begin{abstract}
Objectives: To determine the acceptability of Patient initiated side effects reporting system in their vernacular language. Methods: All the hundred participants were using simple non-probability sampling; participants were given red form and blue form 9 Central drug standard and control suspected adverse effects form for physicians and patients respectively), placed them comfortably and asked to compare and their answers were coded when there were ready to convey the answers. All the questions were closed ended with prior testing with Cronbach alpha value of 0.75 to find suitability, both sheets were give and time allotted for them to get acquaintainted and then questions were put forth. Results: Nearly 65 subjects were aware that even minor side effects should be reported in blue form by themselves while $35 \%$ percentage was not familiar with it. Another significant finding about $66 \%$ people was not familiar with their names or identity such as revealing it in the form. Conclusion: Having adverse drug reaction from
\end{abstract}

and measures taken were laudable; however, suitability and feasibility in our Indian scenario should be improved. Population education may play a key role and appointing social pharmacist is also a key option to alleviate ground level disconnects

Key words: Patient initiated adverse drug reporting, Consumer side effects reporting from, Blue and red from.

Correspondence

Dr. Krishnan Vengadaragava Chary

Associate Professor of Pharmacology, Panimalar Medical College Hospital and Research Institute, Chennai-600123, Tamil Nadu, INDIA

Phone: +919894930069

Email: doctorkrishforu@gmail.com

DOI: 10.5530/jyp.2020.12.94

\section{INTRODUCTION}

Even today, the primary vision of Pharmacovigilance Programme of India is to increase the detection of adverse drug reaction; having fullfledged since 2010, accounting all medical colleges yet India contribution is about 2-3 percent only in ICSR report. Being populous country and widely consuming medicines this number is considered to be very meager.

One of the key pitfall found in a year ago is lack of collaborations, in India traditionally only physicians can report an adverse drug reaction which was not so in developed countries. In United States, England, Japan, etc. paramedical staffs were trained to detect and report an ADRs. For an instance in a meningococcal vaccine study in UK the number of reactions reported by staff nurses and pharmacist were much higher than those detected by physician themselves.

Having realized it Indian Pharmacopoeia Commission (IPC) made number many collaboration to utilize manpower from nursing council if Indian, Pharmacy Council, National Aids Control Organization, Revised Nation Tuberculosis Control Programme workers etc. People under this arena were given training how to fill an adverse drug reaction from super signed by physician and it was sent to local nodal center and it was found to be successful for a period of time. After all these collaboration PvpI incorporated all the private sectors to send their adverse drug reaction to nearest nodal center and still it's functional. ${ }^{1-3}$

Major factor our country facing is multiplicity, despite that as a massive measure India introduces patient/consumer side effects cum suspected adverse effects reporting form in eleven Indian vernacular language and in simple manner called as 'blue form' and our traditional suspected adverse drug reaction in known to be as 'red form' to differentiate from layman language, the ideology behind this if an patient encounter a midler adverse effected following medication he or she can fill the from home itself and can be retuned when she visit next day for routine visit. This does not waste their time and also an adverse drug reaction is also not missed from notification.

PvPI went a step ahead introduced another measure called 'rural pharmacovigilance, this is to suppliant people who lives remote and sometimes people may not visit hospital subsequent day, in these scenarios a health worker visit at each sub center level and collect blue from if any filled by anybody on previous day ${ }^{4,5}$ IPC think optimistic these collaboration, consumer centric side effects reporting form and rural pharmacovigilance would be fruitful measures to determine and collected more number of adverse drug reactions in our scenario. Kalaiselvan, et al. scientific assistant elaborated these as position change of pharmacovigilance programme of India elaborately. Hazra A commented this measure would pose challenges as all Indians capable of identifying adverse drug problem and able to report in the blue from. Our study aims at identifying feasibility and acceptability of both 'red form' and 'blue form' among our common day to day patients and drafting their opinion and comments. ${ }^{6,7}$

\section{MATERIALS AND METHODS}

This study was carried using all the guidelines given Indian code of Medical Research 2017 and informed consent obtained from all the patients after being read our information sheet. STROBE (Strengthening 
of reporting studies epidemiology) guidelines were followed to collect data and to report scientifically robust.

All the hundred participants were using simple non-probability sampling; participants were give red form and blue form, placed them comfortably and asked to compare and their answers were coded when there were ready to convey the answers as shown in Table 1 and 2.

All the questions were closed ended with prior testing with Cronbach alpha value of 0.75 to find suitability, both sheets were give and time allotted for them to get acquaintainted and then questions were put forth. Answers by them noted in MS excel and descriptive statistics were employed and analysis was carried using statistical package of social sciences SPSS versions (24 IBM).

\section{RESULTS}

100 patents were randomly selected by simple non-probability method, outgoing patients 64 were males and 36 were females. 46.7 was their average age and they were belonging to semi urban or peri urban area and with average socio-economic scale III and the literacy rate range from primary school to post graduates and no factors were found to distorting study outcome, Nearly 65 subjects were aware that even minor side effects should be reported while 35\% percentage was not familiar with it. Another significant finding about 66 people was not familiar with their names or identity such as revealing it in the form, detailed finding was tabulated in Tables 1 and 2 .

Table 1: Description of blue and red 'ADR' consumer from.

\begin{tabular}{cccc}
\hline S. no & Question & Yes $(\mathrm{n})$ & No $(\mathrm{n})$ \\
\hline 1. & Have you seen this red form & Males -54 & Males -34 \\
& Females -23 & Females -21 \\
2. & Have you seen this blue form & Males -12 & Males -47 \\
& Females -03 & Females -31 \\
3. & Is these both form look alike except & Males -06 & Males -55 \\
& colour & Females -03 & Females -29 \\
4. & Do you think by seeing subset of table & Males -04 & Males -32 \\
& were adequate & Females -04 & Females -22 \\
5. & Does blue form tend to be simple for to to & Males -46 & Males -11 \\
& be used & Females -34 & Females -00 \\
\hline
\end{tabular}

Table 2: Table depicting tendency of blue consumer 'ADR' form to report side effects.

\begin{tabular}{|c|c|c|c|}
\hline S. no & Question & Yes (n) & No $(n)$ \\
\hline \multirow[t]{2}{*}{1} & \multirow{2}{*}{$\begin{array}{c}\text { Are you able to read all the seven } 7 \\
\text { columns in blue form }\end{array}$} & Males - 45 & Males -19 \\
\hline & & Females - 23 & Females - 11 \\
\hline \multirow[t]{2}{*}{2} & \multirow{2}{*}{$\begin{array}{c}\text { Are you a 'OK' if the name and } \\
\text { addressing asked }\end{array}$} & Males -46 & Males -22 \\
\hline & & Females - 11 & Females -23 \\
\hline \multirow[t]{2}{*}{3} & \multirow{2}{*}{$\begin{array}{l}\text { Will you be able to provide medicine } \\
\text { information were asked to fill }\end{array}$} & Males -24 & Males - 32 \\
\hline & & Females - 11 & Females -22 \\
\hline \multirow[t]{2}{*}{4} & \multirow{2}{*}{$\begin{array}{l}\text { Do you think all the common } \\
\text { medicine taking form is mentioned }\end{array}$} & Males -46 & Males -10 \\
\hline & & Females - 10 & Females - 10 \\
\hline \multirow[t]{2}{*}{5} & \multirow{2}{*}{$\begin{array}{l}\text { Do you think even minor side effect } \\
\text { like rash headache should be written }\end{array}$} & Males -46 & Males - 19 \\
\hline & & Females - 34 & Females - 00 \\
\hline \multirow[t]{2}{*}{6} & \multirow{2}{*}{$\begin{array}{l}\text { Will you given this form to your } \\
\text { doctor }\end{array}$} & Males -32 & Males -22 \\
\hline & & Females - 30 & Females -04 \\
\hline \multirow[t]{2}{*}{7} & \multirow{2}{*}{$\begin{array}{l}\text { Do you this this from should be given } \\
\text { along with prescription sheet }\end{array}$} & Males -35 & Males -11 \\
\hline & & Females - 27 & Females -07 \\
\hline
\end{tabular}

Out of 100 patents were randomly selected by simple non-probability method, outgoing patients 64 were males and 36 were females. 46.7 was their average age and they were belonging to semi urban or peri urban area and with average socio-economic scale III and the literacy rate range from primary school to post graduates and no factors were found to distorting study outcome, Nearly 65 subjects were aware that even minor side effects should be reported while $35 \%$ percentage was not familiar with it. Another significant finding about 66 people was not familiar with their names or identity such as revealing it in the form. Nearly 42 of them gave a study suggestion for our last question this form should be given along with prescription form which we found worthwhile.

\section{DISCUSSION}

This observational study was carried to determine the feasibility and acceptability of patient/consumer initiated direct reporting of adverse reaction with intention of increasing our database. One of the main advantages being its available use vernacular form but this does not come challenges, unlike foreign nations computerized prescription are not in place in our country still at majority of places, many public health centers tend gave one or two medicine say, a diclofenac and ranitidine daily for fibromyalgia on daily basis; in those scenario detecting adverse reaction and complaining it would be a problem.

Yet another diversity exist in patient centric from whether they are adequately knowledge to write names of all concomitant medication or reaction which might be aggravating cause for the side effect, quantifying cumulative dose in a day and other factor playing in a pathogenesis of adverse drug reaction is beyond scientific nature of a common man. Beside these there are hindrance and hesitancy in giving address or names, women tend to show lesser curiosity than men in reporting blue forms etc.

Yet out of 100, one third of the population is optimistic toward selfreporting of side effects and able to give us suggestion which is definitely promising of pharmacovigilance program of India.

There is a study Rehan HS, et al. also concluded though it a welcome move missing information by patient centric side effects filling form would be deterrent in analysis. Beside these our study probably few of the limited studies in India to corroborate our results. ${ }^{8-10}$

Our study also has limitation it was cross sectional, there were no follow up and question were closed ended in order to get their answers quickly and save our outpatient time spent in hospital scenario.

\section{CONCLUSION}

Having adverse drug reaction from and measures taken were laudable; however, suitability and feasibility in our Indian scenario should be improved. Population education may play a key role.

\section{ACKNOWLEDGEMENT}

Prof. Porchelvan, Department of Community Medicine, Saveetha Medical College, Chennai.

\section{CONFLICT OF INTEREST}

The authors declare no conflict of interest.

\section{ABBREVIATIONS}

ADR: Adverse drug reaction; IPC: Indian Pharmacoepia commission; PvPI: Pharmacovigilance programme of India; UK: United Kingdom.

\section{REFERENCES}

1. Kalaiselvan V, Thota P, Singh GN. Pharmacovigilance Programme of India: Recent 
developments and future perspectives. Indian J Pharmacol. 2016;48(6):624-8. doi:10.4103/0253-7613.194855

2. Ahmad A, Patel I, Sanyal S, Balkrishnan R, Mohanta GP. A study on drug safety monitoring program in India. Indian J Pharm Sci. 2014;76(5):379-86.

3. Berrewaerts J, Delbecque L, Orban P, Desseilles M. Patient Participation and the use of Ehealth Tools for Pharmacovigilance. Front Pharmacol. 2016;7:90. doi:10.3389/fphar.2016.00090

4. Sahu RK, Yadav R, Prasad P, Roy A, Chandrakar S. Adverse drug reactions monitoring: Prospects and impending challenges for pharmacovigilance. Springerplus. 2014;3(1):695. doi:10.1186/2193-1801-3-695

5. Bennadi D. Self-medication: A current challenge. J Basic Clin Pharm. 2013;5(1):19-23. doi:10.4103/0976-0105.128253

6. Phillips T, Cois A, Remien RH, et al. Self-reported side effects and adherence to antiretroviral therapy in HIV-infected pregnant women under Option B+: A Prospective Study. PLoS One. 2016;11(10):e0163079. doi:10.1371/journal. pone.0163079

7. McMahon $\mathrm{JH}$, Manoharan A, Wanke CA, et al. Pharmacy and self-report adherence measures to predict virological outcomes for patients on free antiretroviral therapy in Tamil Nadu, India. AIDS Behav. 2013;17(6):2253-9. doi:10.1007/s10461-013-0436-x

8. Tadesse WT, Mekonnen AB, Tesfaye WH, Tadesse YT. Self-reported adverse drug reactions and their influence on highly active antiretroviral therapy in HIV infected patients: A cross sectional study. BMC Pharmacol Toxicol. 2014;15(1):32. doi:10.1186/2050-6511-15-32

9. Hazra A. Consumer reporting of medicine side effects: A dream fulfilled?. Indian J Pharmacol. 2016;48(1):1-2. doi:10.4103/0253-7613.174357

10. Babiarz KS, Suen S, Goldhaber-Fiebert JD. Tuberculosis treatment discontinuation and symptom persistence: An observational study of Bihar, India's public care system covering $>100,000,000$ inhabitants. BMC Public Health. 2014;14(1):418. https://doi.org/10.1186/1471-2458-14-418

Article History: Submission Date : 29-09-2020; Revised Date : 02-11-2020; Acceptance Date : 19-11-20

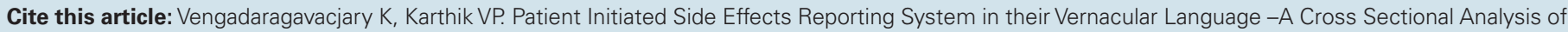
Feasibility and Acceptability in Our Scenario. J Young Pharm. 2020;12(4):370-2. 